\title{
Los chinos y el modelo colonial español en Filipinas
}

\author{
Antonio GarcíA-ABÁsolo \\ Catedrático de Historia de América \\ Universidad de Córdoba \\ Facultad de Filosofía y Letras \\ Plaza del Cardenal Salazar, s/n, 14071, Córdoba, España \\ abasolo@uco.es
}

Fecha de recepción: 05/05/2011

Fecha de aceptación: 15/12/2011

\begin{abstract}
RESUMEN
Filipinas fue el espacio de relación de españoles y chinos durante más de tres siglos. Este trabajo trata de mostrar cómo fueron insertados los chinos dentro del mundo colonial español, las dificultades que se presentaron y los medios empleados para resolverlas. Las funciones desempeñadas por los chinos en Filipinas fueron tan importantes - tan imprescindibles-, que se hicieron las adaptaciones necesarias para conseguir un ámbito de convivencia y entendimiento. Este modelo de relación es un ejemplo de pragmatismo, a pesar de las graves diferencias culturales y religiosas, y muestra, en cierto modo, la validez del sistema imperial español como experiencia de mundo globalizado.
\end{abstract}

Palabras clave: chinos, españoles, relaciones, Filipinas, época colonial.

\section{The Chinese community and the Spanish model of colonization in the Philippines}

\begin{abstract}
The Philippines were the physical space of a long relationship between the Spaniards and the Chinese community for more than 300 years. The aim of this essay is to show how the Chinese were to be inserted in the Spanish colonial world, the difficulties in this process, and the means which were used to solve them. The role played by the Chinese community in the Philippines was of such an importance, of such an essential nature, that every necessary accommodation was made to create an environment of understanding and amicable coexistence. This model of relationship is an example of pragmatism, despite the deep religious and cultural differences, and it proves, to some extent, the validity of the Spanish imperial model as an experience in the first global world.
\end{abstract}

Key words: Chinese, Spanish, The Philippines, Relationships, Colonial Era. 


\section{INTRODUCCIÓN}

El tema de China no es habitual en la historiografía española y, sin embargo, China fue el estímulo para que España saliera a buscar los caminos del mar. Es más, llegar a la China fue el objetivo compartido en distintos momentos por Colón, Magallanes, Cortés y el propio Legazpi, aunque con consideraciones particulares en cada caso. Como resultado de este empeño, el Imperio español ultramarino fue perfilando una parte oriental en la que los chinos tuvieron un protagonismo extraordinario. Aunque es algo poco conocido, españoles y chinos mantuvieron una historia de relaciones estrechas durante más de tres siglos.

El escenario de esta experiencia singular fue el archipiélago filipino y el comienzo se debe poner en los mismos tiempos de Miguel López de Legazpi, es decir, cuando los españoles llegaron a las islas con la intención de establecer un asentamiento permanente en Oriente. En cierto sentido, Legazpi representa la continuidad de las iniciativas franciscanas del siglo XIII en la historia de la aproximación de la Cristiandad Occidental a China. Es bastante razonable pensar que, mientras preparaba su expedición en México, Legazpi recordara los relatos de la presencia franciscana en China a fines del siglo XIII y principios del XIV. Juan Piano de Carpini, Odorico de Pordenone y Juan de Montecorvino habían sido protagonistas de una avanzada de la cristiandad que consiguió establecer la primera organización de la Iglesia católica en la China de los mongoles, con un arzobispo en Pekín (Montecorvino) y siete obispos entre 1307 y 1329.

Estos franciscanos realizaron una labor de gran importancia para el futuro de la expansión de la Cristiandad por Occidente y, desde las perspectivas de la propia historia de la orden franciscana, su actividad misionera y pastoral en China fue un campo de experiencia para los desarrollos misionales que dos siglos después emplearon en las Indias españolas. Georges Baudot considera las crónicas de los franciscanos en China como trabajos etnográficos, indagaciones sobre las sociedades orientales preparatorias de la conquista espiritual e incluso de la política. Indagaciones etnográficas precursoras de los trabajos en México de Motolinía, Andrés de Olmos y Bernardino de Sahagún ${ }^{1}$. Se suele considerar, con sobrado fundamento, que los misioneros que comenzaron la labor evangelizadora en Asia a partir de 1565 aprovecharon la experiencia desarrollada en América, sin embargo, es necesario precisar que los primeros ensayos para evangelizar un mundo distinto los dieron los franciscanos en China.

\footnotetext{
${ }^{1}$ BAUdot, Georges: Utopía e historia en México. Los primeros cronistas de la civilización mexicana (1520-1569), Madrid, Espasa Calpe, 1983. También «Los precursores franciscanos de Sahagún del siglo XIII al siglo XVI en Asia y América», Estudios de Cultura Náhuatl (México), 32 (enero 2001), pp. 159-173. Entre las crónicas franciscanas sobre China hay que destacar la Historia Mongolorum y Liber Tartarorum de Juan Piano de Carpini y los relatos de Odorico de Pordenone.
} 


\section{EL ACERCAMIENTO ESPAÑOL A CHINA}

En los primeros años de presencia española en Filipinas, más o menos entre 1565 y 1570 , los españoles no tuvieron certeza de si la Corona consideraba las islas como asiento definitivo o como plataforma de expansión hacia China. Legazpi escribió varias cartas a Felipe II y al virrey de México preguntando si debía permanecer en Filipinas o seguir a China. Sin embargo, y a pesar de estas dudas, parece que Legazpi se inclinaba más bien por pasar a China; de hecho, su camino por las islas fue un acercamiento a China hasta donde le fue posible. Desde Cebú hizo un recorrido hacia el norte hasta llegar a la isla del Panay y desde allí envió a Martín de Goity, su maestre de campo, hacia Luzón para buscar un asentamiento permanente todavía más al norte. Al mismo tiempo manifestaba al virrey de México, marqués de Falces, con toda claridad que las Filipinas eran de poca importancia, porque hasta entonces el único artículo de posible comercio que había encontrado era la canela. Si Su Majestad pretendía otras cosas de más calidad convenía considerar las islas como escala y buscar un puerto seguro. Un año después, en 1570, precisó más la condición de escala de Filipinas en carta al nuevo virrey de México, Martín Enríquez de Almansa: si su destino era conquistar las Molucas, le parecía que el mejor asentamiento era, en efecto, Cebú, pero si Su Majestad pretendía que llegaran a la costa de China, lo más acertado sería hacer asiento en la isla de Luzón. Con todo, el recorrido de Legazpi hasta Manila era una manera de adelantarse a las respuestas de la corona y del virrey, y también de manifestar claramente sus preferencias en la alternativa entre las Molucas y China ${ }^{2}$. Además, aprovechó todas las oportunidades que tuvo para obtener noticias de China. En Mindoro, una isla cercana a Manila, encontró más de 30 comerciantes chinos que habían sido hechos esclavos por los filipinos, después de haber naufragado los dos champanes con los que hacían comercio. Legazpi los compró, les concedió la libertad y les proporcionó embarcación para regresar a China, después de haberse informado de sus lugares de origen y sus actividades. Otro tanto sucedió en Manila, en donde encontró una comunidad de alrededor de 40 chinos, entre los cuales había algunos cristianos; habían ido de China a Japón y allí habían conocido el cristianismo y se habían bautizado. En resumen, Legazpi actuó en estos primeros años preparando el terreno para el paso a China con los medios que tuvo a su alcance: poniéndose lo más cerca posible de China y consiguiendo toda la información que pudo recabar mediante un trato exquisito con los chinos que se encontró en su camino. Conviene añadir que las preferencias de Legazpi por el asentamiento español en China no pueden ser consideradas como una excentricidad; los portugueses estaban convencidos de que las intenciones últimas de los españoles eran pasar de Filipinas a China ${ }^{3}$.

También los eclesiásticos pensaron en estos primeros años que Filipinas era solo lugar de paso para entrar en China. Martín de Rada, provincial de los agustinos y máxima autoridad eclesiástica entonces, había deducido de las informaciones tomadas a un chino, al que juzgaba de posición relevante, que fácilmente y no con mucha

\footnotetext{
2 Archivo General de Indias (en adelante AGI), Filipinas, 6: Legazpi al virrey marqués de Falces. Manila, 7 de julio de 1569. AGI, Patronato, 24: Legazpi al virrey Martín Enríquez de Almansa. Panay, 25 de julio de 1570.

3 AGI, Filipinas, 6: Legazpi al virrey marqués de Falces. Manila, 7 de julio de 1569.
} 
gente los chinos podrían ser dominados ${ }^{4}$. Rada fue el primer embajador oficial del gobernador de Filipinas en la provincia china de Fuquien, la que más contacto tuvo siempre con Filipinas, entre junio y julio de 1575. Es interesante constatar que, después de esta experiencia, cambió su primera opinión y precisó que la labor principal de los religiosos de Manila era la evangelización de Filipinas:

Los más, pretendiendo (ir a China) para buscar a Dios, se buscan a sí mismos y una miserable honrilla de ir a tierra tan grande y entre tanta gente y bautizar a muchos, como todo esto no está en su mano sino en la de Dios ${ }^{5}$.

Se podría decir que tanto Martín de Rada como Legazpi, hombres ambos de gran prudencia, fueron matizando sus impresiones sobre China hasta consolidar una visión eminentemente práctica. Una vez determinado oficialmente que su destino era Filipinas, Legazpi había optado por dejar las cosas como las había encontrado, es decir, hacer que los chinos continuaran su comercio con Filipinas pero haciendo sus intercambios con los españoles: "No he querido enviar gente allá por no los alterar ni alborotar, pues la contratación suya la tenemos cierta y adquirida por su propia voluntad" ". Hubo otras opiniones, como veremos, pero las de Legazpi y Rada marcaron la posición pragmática que tendió a predominar en las relaciones entre españoles y chinos en Filipinas, y esto debe entenderse en los dos sentidos, tanto por parte de los españoles como por parte de los chinos.

Guido de Lavezaris, sucesor de Legazpi en 1571, tuvo la oportunidad de establecer contactos directos con China continental: Lavezaris envió en 1575 una embajada a Fuquien compuesta por los agustinos Martín de Rada y Jerónimo Marín y los soldados Miguel de Loarca y Pedro Sarmiento. El motivo fue conseguir un lugar en China para establecer una línea de comercio y licencia para que los misioneros pudieran predicar el cristianismo en China. Estuvieron tres meses recorriendo la provincia y entrevistándose con unos mandarines propensos al entendimiento con Manila. Fue un buen momento para el acercamiento porque chinos y españoles se habían unido a través de un enemigo común, el pirata chino Limahon. Se había llegado al acuerdo de que las peticiones españolas serían atendidas, a cambio de la entrega de Limahon, que había fracasado en su intento de tomar Manila. Pero las buenas perspectivas de entendimiento se frustraron porque Limahon consiguió escapar y por la llegada de Francisco de Sande como nuevo gobernador de Filipinas?

Precisamente Francisco de Sande fue uno de los más enérgicos partidarios del asentamiento español en China por la vía de las armas y consecuentemente acabó con

\footnotetext{
${ }^{4}$ AGI, Filipinas, 79: Cartas de Martín de Rada, provincial de los agustinos, a Martín Enríquez, virrey de Nueva España. Cebú, 8 de julio de 1569 y AGI, Patronato, 24, R22.: Manila, 10 de agosto de 1572.

${ }_{5}^{5}$ Carta de Martín de Rada a Juan Cruzat (OSA). Calumpit, 15 de julio de 1577 (Rodríguez, Isacio: Historia de la Provincia Agustiniana del Santísimo Nombre de Jesús, Vol. 14, Manila, 1974, p. 82).

${ }^{6}$ AGI, Patronato, 24, R23: Legazpi a Martín Enríquez de Almansa, virrey de Nueva España. Manila, 11 de agosto de 1572 .

7 Biblioteca Nacional de París, FE, Mss, 325, 33-44. Martín de Rada a Alonso de la Veracruz. Borneo, 25 de abril de 1578 (cit. por Rodríguez: op. cit., Vol. XV, Manila, 1978); Archivo Histórico Nacional, Diversos, Cartas de Indias, 238: Martín Enríquez al rey. México, 31 de octubre de 1576.
} 
la política de acercamiento anterior ${ }^{8}$. Siguiendo la línea de Sande, el jesuita Alonso Sánchez diseñó un proyecto de conquista de China que se estudió oficialmente en Manila en 1586 y que fue presentado a Felipe II por el propio Alonso Sánchez, junto con un memorial muy amplio de peticiones sobre las mejoras que había que aplicar en Filipinas. Felipe II aprobó muchas de las peticiones de ese memorial que el jesuita le presentó en nombre de la comunidad de Manila, pero rechazó con rotundidad el proyecto de conquista de China9.

\section{EL CHINO EN LA SOCIEDAD COLONIAL}

Me he detenido más en el tratamiento de la vía diplomática de acercamiento a China, porque es la que dio lugar a un proceso de conocimiento mutuo entre españoles y chinos que terminó por decantarse en un entendimiento pragmático. Dos pueblos de culturas tan diferentes supieron descubrir que podían establecer un modelo de convivencia, en la medida en la que fueran capaces de encontrar intereses comunes, o al menos complementarios. Pero antes de considerar con detenimiento ese modelo, es preciso dejar claramente expuesto que los españoles, aún admitiendo la presencia de los chinos en su sociedad, no tuvieron la condición de súbditos y siempre se incorporaron como extranjeros. No es un exceso decir que se incorporaron, porque los chinos fueron una pieza fundamental en la organización del sistema colonial español en Filipinas. Es más, cuando los españoles de Filipinas se referían a extranjeros y sangleyes lo expresaban así: considerándolos extranjeros pero distinguiéndolos como sangleyes. Juan Bautista Uriarte y Francisco Sánchez de Tagle, alcaldes ordinarios de Manila, expusieron los problemas causados por los chinos que adulteraban la moneda circulante en Filipinas:

De manera que en moneda grande las pérdidas son de un $25 \%$ y en la menor todavía más. De aquí se sigue un daño general porque el desorden de la moneda afecta a los tratos y a los precios de los extranjeros y sangleyes, que suben.

Ignacio Martínez de Alzate, vecino de Manila de 50 años de edad, nos permite entrar algo más en estas sutilezas:

Hablando con todo el respeto, le parece que está fuera de toda policía y buen gobierno que se permita a unos extranjeros, como son los sangleyes, buscar y crecer caudales considerables, como lo ha manifestado la experiencia ${ }^{10}$.

\footnotetext{
${ }^{8}$ AGI, Filipinas, 6: Francisco de Sande al rey. Manila, 7 de junio de 1576. El gobernador Sande había llegado a Manila el 25 de agosto de 1575.

9 Ver Ollé, Manel: La invención de China. Percepciones y estrategias filipinas respecto de China durante el siglo XVII, Wiesbaden, Ed. Rodery Ptak y Thomas O. Höllmann, 2000, Vol. 9. También Porras, José Luis: Sínodo de Manila de 1582, Madrid, CSIC, 1988.

10 Declaraciones de don Juan Bautista Uriarte, regidor, y del general don Francisco Sánchez de Tagle (de mancomún), ambos alcaldes ordinarios de Manila y su jurisdicción, y del capitán don Ignacio Martínez de Alzate, vecino de Manila. Manila, 6 de febrero de 1731. Proceso abierto por la muerte de Sengco, sangley infiel encontrado el 11 de septiembre de 1730 ahorcado en su propia tienda del parián de los sangleyes. Entre sus pertenencias se
} 
Una declaración contundente que incide en que los chinos debían ser tratados como extranjeros, aunque en la realidad no lo pareciesen.

Como he señalado, en su recorrido desde Cebú hasta Luzón, Legazpi se encontró en varias ocasiones con mercaderes chinos, a los que se refirió siempre en sus cartas al rey y al virrey de Nueva España como indios chinos, denominación que no utilizó para referirse a los filipinos, aunque también los asumió con la categoría de indios. Es posible que Legazpi estuviera mostrando sus propios proyectos al hacer esta consideración de los chinos. En sus perspectivas de un paso inmediato a China podría parecer razonable que utilizara esta categoría de indios chinos, es decir, de indios como posibles súbditos de la corona española, como lo eran los indios americanos y los recién incorporados filipinos. Sin embargo, no pasó mucho tiempo para que, a los chinos que llegaban anualmente a Filipinas y a los que se asentaban en las islas, se les llamara simplemente chinos o sangleyes, pero sin el apelativo de indios, porque claramente se percibieron como otros.

Estas apreciaciones de Legazpi sobre la condición jurídica de filipinos y chinos son valiosas, teniendo en cuenta que era un letrado de larga experiencia: había ejercido en el País Vasco y después en el virreinato de Nueva España, en el que pasó suficientes años como para conocer en profundidad los aspectos legales y jurídicos del sistema administrativo colonial ${ }^{11}$. Tampoco está de más considerar que sus estimaciones las dejó expuestas en cartas oficiales al rey de España y al virrey de México, siendo él la máxima autoridad en Filipinas.

La denominación de indios chinos, usada por Legazpi en Filipinas para referirse a los chinos, la encontramos en la documentación del virreinato de Nueva España en la misma época de finales del siglo XVI. No obstante, en el virreinato continuó usándose durante toda la época colonial y se aplicaba a los filipinos que llegaban a Acapulco en el galeón que todos los años llevaba mercancías orientales desde Manila. Muchos de estos eran marineros que regresaban con el galeón, pero otros se quedaron en Nueva España, preferentemente en la costa del Pacífico, aunque terminaron repartiéndose por todas partes, incluso en las zonas mineras del norte. El problema es que, además de los filipinos, probablemente también fueron conocidos como indios chinos los demás asiáticos que entraron en el virreinato por Acapulco. Aunque la historiografía es muy parca en este tema, sabemos que entre 1565 y 1700 entraron 7.200 asiáticos por Acapulco procedentes de Manila. De estos, eran esclavos 3.630, la mayoría procedentes del Estado da India portugués y negociados por los portugueses con los vecinos de Manila. A estas entradas oficiales, es necesario añadir una cantidad muy difícil de estimar de los que se repartieron fraudulentamente por la costa del Pacífico mexicano, antes de llegar a Acapulco ${ }^{12}$. En conjunto no pudieron ser muchos porque

encontraron recortes de plata que parece proceder de moneda sellada. Ante el oidor Francisco López Adán, Manila, 6 de febrero de 1731, AGI, Filipinas, 202, R1, N4.

11 Puede verse un análisis de las disposiciones que afectaban a los chinos en la legislación colonial en DíAzTrechuelo, María Lourdes: «Relaciones entre españoles y chinos en Filipinas: su regulación legal (siglos XVI a XIX)», en Pinard, Gustavo E. y otros (ed.), Libro Homenaje In Memoriam Carlos Díaz Rementería, Huelva, Universidad de Huelva, 1998, pp. 239-254.

12 Agradezco a la doctora Déborah Oropeza la información que me ha facilitado sobre su tesis doctoral, titulada Los "indios chinos" en la Nueva España: la inmigración de la nao de China, 1565-1700, México, El Colegio de 
la carrera del Pacífico (Manila-Acapulco) se hizo mediante un galeón y en algunas ocasiones dos, y aunque los astilleros de Filipinas construían navíos de gran capacidad, las posibilidades de transporte eran limitadas. Además, el viaje desde Manila a Acapulco duraba de cinco a siete meses, en los que las dificultades de la navegación y las enfermedades, especialmente el escorbuto, reducían notablemente tripulaciones y pasajeros. Algunos que padecieron los tormentos de este viaje nos han dejado valiosos testimonios en escritos, en los que podemos encontrar reflejada también la importancia de Acapulco como vía de entrada de asiáticos y de mercancías orientales ${ }^{13}$.

Por otra parte, es evidente la presencia de asiáticos por el asentamiento de formas técnicas y estéticas de origen chino y filipino en la artesanía de Nueva España. Esta influencia fue más intensa en la costa del Pacífico mexicano, desde Acapulco, donde atracaba el Galeón de Manila, hasta Nueva Galicia. No sólo introdujeron elementos nuevos, sino que también enriquecieron con notas orientales la artesanía tradicional mexicana, como sucedió con las técnicas prehispánicas de los indios tarascos, perfeccionadas bajo la influencia de los productos chinos que llegaban de Manila. En estas regiones de Chiapas, Guerrero, Michoacán, Colima y Jalisco, en las que la influencia asiática era mayor, se fraguó una tradición artesana que abasteció el gusto renovado de los mexicanos por decorar sus casas, palacios, conventos e iglesias con los diseños orientales. Los propios artesanos mexicanos terminaron influenciándose por este nuevo estilo, que se tradujo en la proliferación en la decoración de flores exóticas, o en el perfeccionamiento técnico y estético en la elaboración de productos como el maque, a imagen y semejanza de las lacas chinas. En maque se hicieron muchas bateas profusamente decoradas, muy utilizadas en la vida cotidiana en la época colonial como bandejas o recipientes para diversos menesteres, entre ellos guardar alimentos. También muebles con decoración oriental, como arcones, cofres y, sobre todo, biombos. Por otra parte, una muestra clara de la presencia oriental fue la introducción en las regiones del Pacífico mexicano de una bebida llamada tuba, de origen nítidamente filipino. Es una bebida refrescante que se obtiene de las flores de la palma de coco, que todavía en la actualidad es popular en algunas regiones, especialmente en Coli$\mathrm{ma}^{14}$. En definitiva, aunque falten trabajos que estudien la presencia de filipinos en las zonas del Pacífico mexicano próximas a Acapulco, es considerada tan importante como para que el aporte humano asiático se haya incorporado habitualmente a los estudios generales sobre las comunidades indias ${ }^{15}$.

México, 2008. Un resumen de este trabajo se puede ver en "Asian inmigration to the viceroyalty of New Spain", paper presentado en la American Historical Association Annual Meeting, New York, January 2009.

13 Especialmente interesantes son dos descripciones del puerto y de su actividad, una de CarLetTI, Francesco: Razonamientos de mi viaje alrededor del mundo (1594-1606), México, UNAM, 1976, p. 64 y otra de GEMELLI CARERI, Giovanni Francesco: Viaje a la Nueva España, México, UNAM, 1983. Gemelli Careri hizo su viaje a fines del siglo XVII.

14 Fernández, Miguel Ángel: La Nao de China, Monterrey, 1998, pp. 134-158. En este precioso libro, el autor abunda en estas influencias en el capítulo titulado "A imagen y semejanza", acompañado de excelentes ilustraciones. La importancia de los productos del comercio del Galeón de Manila en Nueva España también queda bien puesta de manifiesto en el clásico estudio de SchurTz, W.L.: El galeón de Manila, Madrid, Ediciones de Cultura Hispánica, 1992, pp. 309-324.

${ }^{15}$ En su estudio sobre la evolución de las comunidades indígenas de Guerrero, Danièle Dehouve (Entre el caimán y el jaguar: los pueblos indios de Guerrero, México, Centro de Investigaciones y Estudios Superiores en Antropología Social, Instituto Nacional Indigenista, 1994) incorpora a los negros y a los chinos, término empleado 
Estas evidencias no alteran la realidad de que en la situación actual de nuestros conocimientos no es posible hacer una distinción entre los asiáticos de Nueva España en la época colonial. He mencionado que entraron esclavos, pero la mayoría de ellos no fueron filipinos. A partir de los años ochenta del siglo XVI la esclavitud filipina se prohibió con bastante eficacia; los filipinos que se embarcaron en Manila con destino a Acapulco lo hicieron normalmente como súbditos libres de la corona española. Del comportamiento de algunos grupos de filipinos asentados entre Acapulco y Jalisco a fin del siglo XVI y principios del siglo XVII, estudiado a través de testamentos, se puede comprobar que tuvieron una gran capacidad de adaptación tanto al mundo indio como al español. Su ámbito natural era el de los pueblos de indios, porque su condición jurídica era de indios, pero su naturaleza singular de indios chinos, que era como se les conocía y como ellos mismos se conocían entre sí, llevó al menos a algunos de ellos a moverse con bastante facilidad también en el mundo de los españoles ${ }^{16}$.

La consolidación de la denominación indio chino en Nueva España, aplicada a los filipinos, significaba su identificación legal de indios dentro del Imperio español. En principio, en el ámbito americano no importaba demasiado el error antropológico, porque servía para precisar que los filipinos eran los únicos asiáticos con capacidad de ser súbditos libres de la corona. Esto hace buenas las apreciaciones de Legazpi cuando denominó a los chinos que conoció en Filipinas como indios chinos, teniendo en cuenta que en el momento en que las hizo sus planteamientos de futuro implicaban la incorporación de China al Imperio.

\section{LOS CHINOS Y EL MODELO COLONIAL ESPAÑOL EN ASIA}

A pesar de que los intentos de establecer relaciones directas con China y de asentarse allí mediante la vía pacífica y la militar fracasaran, los españoles y los chinos terminaron encontrándose en Filipinas. Muy pronto se estableció en Manila un mundo chino que participó plenamente en la articulación del sistema colonial español en Oriente, hasta el punto de que, sin los chinos de Manila, a los que los españoles llamaban sangleyes, es difícil imaginar que la ciudad hubiera sobrevivido y que la misma presencia española en Filipinas hubiera sido posible.

Cientos de chinos llegaban cada año con las mercancías que la comunidad española de Manila compraba para embarcar en el galeón que cruzaba el Pacífico y vender en Acapulco. De ordinario se quedaban en Manila alrededor de medio año, el tiempo que empleaban en vender sus productos, y después debían regresar a China. Sin embargo, la realidad fue que muchos se quedaron en Manila y sus alrededores como comerciantes y como artesanos de todos los oficios imaginables. Después fueron extendiéndose por las provincias y participando también en

en este caso para designar a los filipinos.

${ }^{16}$ García-Abásolo, Antonio: «Filipinos on the Mexican Pacific Coast during the Colonial Period (1570-1630)», en Into the Frontier: Studies in Spanish Colonial Philippines, previsto para publicar en 2011 por la University of Asia and the Pacific, Manila. 
las economías locales, de manera que terminaron controlando la mayor parte del comercio mayor y todo el menor, porque no era fácil competir con ellos. Durante todo el período colonial, un grupo de españoles muy pequeño vivió dependiendo de una comunidad china que siempre fue mucho mayor, tanto para obtener los beneficios del comercio con México, que eran la fuente principal de recursos de los españoles, como para proporcionarles todos los productos que necesitaban en la vida cotidiana. Los chinos abastecían Manila de alimentos, construían edificios, eran plateros, zapateros, cerrajeros, herreros y, en general, servían a la comunidad de Manila todo lo que pudiera desear. Al final, hasta se especializaron en productos que no eran de la tradición cultural china pero que demandaba el mercado español, como imágenes religiosas cristianas o tipos de tejidos que llegaron a hacerse populares en América y en España, como los famosos mantones de Manila, una prenda que probablemente la hacían los chinos para venderla a los españoles de Filipinas ${ }^{17}$.

Domingo de Salazar, primer obispo de Manila, hizo en 1588 una rica descripción de la actividad del parián, el barrio de los chinos situado fuera de las murallas de la ciudad y siempre al alcance de sus cañones. Aunque en 1588 el parián tenía una historia muy corta (lo fundó el gobernador Gonzalo Ronquillo en 1580), ya estaba formado por cuatro calles con cuatro filas de edificios en los que había 150 tiendas y 600 chinos residiendo habitualmente. Salazar hizo referencia también a otros chinos que ya se habían establecido fuera del parián: 100 al otro lado del río Pasig y 300 distribuidos por las orillas y en la ribera del mar, la mayoría casados y muchos de ellos cristianos.

Sobre la actividad comercial de Manila, en la que el protagonismo principal lo tenían los chinos, decía el obispo:

Hay mercado público en la Plaza de Manila todos los días de cosas de comer, como gallinas, puercos, patos, caza de venados, puercos de monte y búfalos, pescado, leña y otros bastimentos, y hortalizas y muchas mercaderías de China que se venden por las calles. Cada año llegan de China a Manila veinte navíos o más de mercaderías, cada uno con cien hombres o más, que tratan en Manila desde noviembre hasta mayo, siete meses en los que comercian, y después regresan. Llevan de 200.000 pesos para arriba en mercaderías, además de 10.000 en bastimentos, como harina, bizcochos, azúcar, manteca, naranjas, nueces, castañas, piñones, higos, ciruelas, granadas, peras y otras frutas, tocinos y jamones, en tanta abundancia que todo el año hay sustento para la ciudad y para el aprovisionamiento de las armadas y flotas; y llevan muchos caballos y vacas de los que se va abasteciendo Filipinas. De dos años a esta parte llegan navíos de particulares de Japón, Macao, Siam y de otras partes con mercancías para tratar en Manila, de que los unos y los otros se van aficionando a nuestra amistad y trato y se van convirtiendo muchos de las dichas naciones. Y de esta tierra llevan para la suya reales de plata, oro, cera, algodón y palo para tintas y caracoles menudos, que es como moneda en su tierra y de mucho provecho para otras cosas y los estiman en mucho, y lo que ellos traen

\footnotetext{
${ }^{17}$ Ver sobre esto el interesante estudio de Ortiz Armengol, Pedro: Letras en Filipinas, Madrid, Dirección General de Relaciones Culturales y Científicas, 1999, especialmente "Los chales bordados", pp. 215-222.
} 
es seda en seda labrada y rasos, damascos negros y de colores, brocateles y otras telas, de que ya es muy común la noticia, y mucha ropa de algodón blanca y negra y los dichos bastimentos ${ }^{18}$.

La variedad de productos chinos en Manila era extraordinaria, pero el producto fundamental de las transacciones y de los envíos a Acapulco era la seda; de hecho, el parián era conocido también como alcaicería, es decir, mercado de seda. Las exportaciones de seda terminaron identificándose con China, tanto por su abundancia como porque el cultivo de moreras y la artesanía de la seda representaban muy bien la armonía entre el desarrollo agrícola y la producción artesanal, valores que Confucio había señalado como esenciales para la sociedad china.

Lo que los españoles podían ofrecer a cambio era la plata de las minas americanas, y precisamente eso era lo que los chinos deseaban. La corriente de plata americana a China a través de Filipinas fue tan abundante, que muy pronto las monedas mexicanas fueron usadas en China para los intercambios. Los chinos de Filipinas controlaron toda la plata que llegaba cada año desde Acapulco y dominaron por completo la vida comercial de Filipinas. Según datos del Banco de México, durante los doscientos cincuenta años del comercio del galeón, llegaron a Filipinas 400.000.000 pesos mexicanos, casi todos destinados a la compra de productos chinos. Por tanto, se puede decir que entre los españoles y los chinos se estableció una relación de dependencia mutua en la que unos y otros aportaban lo que necesitaban; no siempre la convivencia fue pacífica, pero la realidad fue que llegaron a entenderse y que pocas naciones europeas pueden mostrar una experiencia de relación tan larga con el mundo chino como la que tuvieron los españoles de Filipinas.

El oidor Antonio de Morga, testigo cualificado de la vida de Manila entre 1595 y 1603, nos dejó muchas noticias sobre los chinos. En cuanto a las transacciones comerciales con los españoles, hizo observaciones tan interesantes como estas:

El precio de ordinario de las sedas crudas y tejidas y manterías, que es lo más grueso que traen, se hace despacio y por personas que lo entienden, así por parte de los españoles como de los sangleyes, y lo que se les da por ellas es plata y reales, que no quieren oro ni otros algunos rescates ni los llevan a la China. Y todo el empleo ha de estar hecho en todo el mes de mayo, poco más o menos, para que el sangley pueda volver y para que el español lo tenga apunto para cargarlo en los navíos que por fin de junio salen a la Nueva España, aunque también los más granjeros y sobrados de dineros lo suelen hacer después, a precios más moderados y lo guardan para otro año. Y algunos sangleyes, con la misma intención, se quedan en Manila con parte de sus mercaderías cuando no han tenido buena salida de ellas para irlas vendiendo más despacio. Es gente muy práctica e inteligente en la mercancía y de mucha flema y reportación para hacer mejor su negocio, y saben fiar y hacer comodidad liberalmente a quien saben les trata verdad y no les ha de hacer falta en la paga al tiempo que ponen. Por otra parte, como gente sin ley ni conciencia y tan codiciosa, hacen mil fraudes y engaños en las mercaderías, que es menester estar muy atentos y conocerlas para no ser engañados los

18 AGI, Filipinas, 74: Informe del obispo de Manila, Domingo de Salazar, sobre el censo de las islas Filipinas. Manila, 25 de junio de 1588 . 
compradores, los cuales también se desquitan en malas pagas y trampas que les hacen, que en uno y otro tienen de ordinario los jueces y audiencia bien en qué ocuparse ${ }^{19}$.

Estas actitudes, que suponían algo así como una tolerancia compensada entre españoles y chinos, respondían a los criterios pragmáticos que privaron entre grupos de culturas tan diversas. Normalmente fueron posibles cuando no quedaban afectadas cuestiones esenciales de una u otra parte, por eso los problemas más difíciles de resolver fueron los de carácter religioso, en los que la transigencia no parecía posible. En los demás, la tolerancia compensada llegó al punto de generar en ocasiones mecanismos de integración en el delito. Por ejemplo, en los sistemas de evaluación de las mercancías de los champanes chinos que llegaban a Manila, necesarios para fijar el almojarifazgo. El fiscal de la audiencia de Manila recibía de los capitanes chinos una relación de la mercancía cargada y sobre ella el gobernador determinaba la cantidad a pagar, sin necesidad de comprobar la veracidad de lo declarado. El sistema le venía bien a los capitanes porque pagaban menos de lo que correspondía y a las autoridades coloniales que participaban (oficiales reales, fiscal y gobernador) porque recibían regalos en mercancías chinas ${ }^{20}$. El fiscal Francisco Leandro de Viana, uno de los ilustrados más eficaces de Filipinas, se mostró asombrado de la familiaridad con que este procedimiento fraudulento se había consolidado en las islas:

Este es, Señor, el asunto más digno de mejorarse en estas islas por las infelices consecuencias que resultan de él, pues por una parte se ve abandonado el Real servicio de V.M., que solamente sirve de pretexto a los gobernadores, y aun a los fiscales y oficiales reales, para sus adelantamientos injustos, y por otra se ve ultrajado el nombre de Dios y despreciada la religión del juramento, únicamente por no dar a V.M. lo que al fin vienen a percibir vuestro gobernador, fiscal y oficiales reales. Es tan absolutamente cierta la falsedad de la mencionada lista y la del juramento que hacen los capitanes, que apenas habrá uno en estas islas que no lo sepa, pero sin embargo de esta publicidad y notoriedad, necesito hacer demostrable la verdad de lo uno y de lo otro, como que de aquí pende el remedio de las ofensas que se hacen a Dios y a VM²1.

Por otra parte, en la Manila española se pueden encontrar los arquetipos más controvertidos, y ya no tan vanguardistas, que tiene planteados nuestro mundo occidental, como la globalización y la multiculturalidad. El abigarramiento étnico de la ciudad la convirtió en la más exótica del dominio colonial español en su conjunto. Probablemente fue uno de los experimentos más originales de convivencia multiétnica en el ámbito conocido por los europeos: en Manila había, entre otros, filipinos,

\footnotetext{
19 Morga, Antonio de: Sucesos de las Islas Filipinas, nueva edición enriquecida con los escritos inéditos del mismo autor, ilustrada con numerosas notas que amplían el texto y prologada extensamente por W.E. Retana, Madrid, 1909 , p. 218.

20 Un planteamiento más general de esta cuestión en GARCíA-ABÁsolo, Antonio: «La Audiencia de Manila y los chinos de Filipinas. Casos de integración en el delito», Homenaje a Alberto de la Hera, México, Instituto de Investigaciones Jurídicas, UNAM, 2008, pp. 339-368. Del mismo autor, «Relaciones entre españoles y chinos en Filipinas. Siglos XVI y XVII», en CABrero, Leoncio (coord.): España y el Pacífico, Madrid, 2004, Tomo II, pp. 231248. Trabajos disponibles en http://www.uco.es/aaf/garcia-abasolo/

${ }^{21}$ AGI, Filipinas, 577: Francisco Leandro de Viana, fiscal, al Rey. Manila, 4 de mayo de 1760.
} 
chinos, japoneses, indios, armenios, españoles europeos y españoles americanos, indígenas americanos y negros. No vivieron completamente juntos, pero sí habitualmente cercanos y se las ingeniaron para encontrar las soluciones adecuadas a los problemas cotidianos, de ordinario con un sorprendente sentido práctico. El jesuita Pedro Murillo Velarde, que vivió en Manila a mediados del siglo XVIII, es muy explícito al respecto:

Estando una hora en el Tuley o Puente de Manila se verán pasar casi todas las naciones de Europa, Asia, América y África; se verán sus trajes y se oirán sus lenguas. El prodigio es que todos estos para comunicarse entre sí hablan en español; pero cómo. Cada nación ha formado una jerigonza por donde se entienden. Yo oí un día un gran pleito entre un sangley, un armenio y creo que un malabar; todos hablaban español y yo no entendía a ninguno, por no haber estudiado entonces sus vocabularios ${ }^{22}$.

\section{FILIPINAS EN EL IMPERIO ESPAÑOL}

Más adelante voy a tratar de cuestiones más específicas en las relaciones entre españoles y chinos. Para entenderlas es preciso conocer, aunque sólo sea sumariamente, el marco en el que españoles y chinos se desenvolvieron: la incardinación de Filipinas dentro del Imperio español, es decir, la incorporación de un territorio singular a una administración colonial ya conformada.

Filipinas se estructuró como una provincia dependiente del virreinato de México, con un gobernador que en la práctica era independiente porque el virrey estaba demasiado lejos: dos meses en los buenos casos duraba el viaje de Acapulco a Manila y entre cinco y siete meses, como ya vimos, el de Manila a Acapulco. La administración de justicia la ejercía la audiencia, un tribunal de cuatro o cinco magistrados, y la administración eclesiástica contaba con una diócesis archiepiscopal y tres diócesis episcopales sufragáneas en Cebú, Nueva Cáceres y Nueva Segovia. El gobernador, la audiencia y el arzobispo residían en Manila, en donde había también una guarnición permanente para la protección de la ciudad y de la provincia. Fuera de Manila, los distritos se gobernaban por medio de gobernadores locales llamados alcaldes mayores, pero en los lugares alejados de Manila fueron los misioneros los que hicieron toda la labor, la suya de evangelización y en cierto modo la de occidentalización e incluso la de gobernantes, en cuanto que eran el canal por el que llegaban las disposiciones de la administración colonial de Manila a los lugares más alejados del archipiélago. En muchos de estos lugares de Filipinas, las únicas caras españolas que veían los filipinos eran la de los misioneros y algunas veces la del alcalde mayor.

Por eso, en último término, los mercaderes terminaron siendo los auténticos dominadores del ritmo de la vida de Manila: en el comercio estaban la riqueza y el poder para unos pocos y la posibilidad de vivir establemente para todos. Manila quedó así marcada como un enclave occidental en un mundo oriental, sostenido por los inter-

${ }^{22}$ Murillo Velarde, Pedro: Geographía histórica de las Islas Philipinas, del África y de sus islas adyacentes, Tomo VIII, Madrid, 1752, pp. 52. 
cambios con México. En 1593 se estableció el monopolio del comercio con China a favor de los vecinos de Manila. Podrían cargar en Manila mercancía por valor de 250.000 pesos y venderla en Acapulco aproximadamente por el doble, es decir, 500.000; en 1702, el valor de la carga se estableció en 300.000 y la venta en 600.000; en 1734 subió hasta 500.000 y la venta a un millón; y en 1776 una nueva subida hasta 750.000 pesos y la venta a 1.500 .000 pesos, que permaneció hasta la desaparición de la carrera del Pacífico en $1815^{23}$. Tenían derecho a carga los vecinos de la ciudad que hubieran residido en Manila al menos durante diez años, porque los privilegios del comercio estaban dirigidos a estimular que acudieran pobladores de España y de México. El sistema era bueno por la rentabilidad del comercio con Acapulco, pero la limitación de la carga, a fin de cuentas, redujo las posibilidades de enriquecerse con el comercio a los vecinos de Manila ${ }^{24}$. Representantes de mercaderes mexicanos canalizaban inversiones procedentes del virreinato, y los manileños podían recurrir a préstamos de las obras pías, de las órdenes religiosas o de los mismos chinos. En el siglo XVIII, las obras pías, en particular la Hermandad de la Santa Misericordia de Manila, prestaron a los cargadores del galeón millones de pesos a un interés que osciló entre el 20 y el $50 \%{ }^{25}$. Los chinos participaron en el control del comercio del galeón porque fueron los abastecedores de las mercancías y también porque participaron en la financiación de las cargas preparadas por los vecinos de Manila para la venta en la feria de Acapulco. De hecho, los pesos que llegaban de Acapulco terminaban en su mayor parte en manos de los chinos.

Pero conviene dejar claramente expuesto que el Galeón de Manila fue mucho más que una línea comercial, aunque como línea comercial proporcionara unas ganancias fabulosas. Gemelli Careri, el viajero de Nápoles que navegó de Manila a Acapulco en 1697, dice que se conseguían ganancias de entre 150 y $200 \%$ para los mercaderes y del $9 \%$ para los agentes. Era habitual aceptar préstamos al 50\% con la seguridad de que se obtendrían beneficios ${ }^{26}$.

\section{ASPECTOS DE LAS RELACIONES ENTRE ESPAÑOLES Y CHINOS}

En Manila, españoles y chinos siempre tuvieron el convencimiento de que su dependencia era compartida: los españoles dependían de los chinos para casi todo y los sangleyes dependían de los españoles para lo que les interesaba. Lo que les interesaba sobre todo era la plata, aunque también en Filipinas, especialmente en los alrededores de Manila, la vida era mucho más deseable que en el sur de China. De otra forma, no sería posible comprender cómo, después de los alzamientos de los chinos, que se produjeron en varias ocasiones durante el siglo XVII, y de las represiones tan contundentes de los españoles, siempre y rápidamente los chinos regresaban, los españoles

\footnotetext{
${ }^{23}$ SHURZ: op. cit. (nota 14), p. 162.

24 Díaz-Trechuelo, Lourdes: «Historia económica de Filipinas en la segunda mitad del siglo XVIII», Manila, Cuadernos del Centro Cultural, 1978, pp. 9 y 10.

25 SHurz: op. cit. (nota 14), p. 171.

26 Gemelli Careri, Giovanni Francesco: Giro del Mondo, Venecia, 1719, en Leonard, Irving: Viajeros por la América Colonial, México, FCE, 1992, pp. 136-137.
} 
los admitían y se recuperaba el mundo de dependencia mutua. Además, con una presencia china que cada vez se hizo más abundante y se extendió por todas las islas. A fines del siglo XVI, los propios chinos de Manila ofrecieron ayuda a las autoridades españolas para entrar en China, con el objeto de desviar la atención de los españoles hacia China continental y asegurar la vida tranquila y próspera de su comunidad en la comarca de Manila ${ }^{27}$.

Vamos a ver los problemas que se plantearon en las relaciones entre los españoles y los chinos y los remedios que los españoles estimaron adecuados para resolverlos. El problema de fondo era que los españoles contemplaban a los chinos con una actitud que se movía entre la alteridad, el temor y su importancia para la economía de las islas; los consideraban como unos extranjeros imprescindibles. En la idea española de los chinos entraron desde el primer momento dos notas fundamentales: la necesidad de contar con ellos y el temor que les producía tener tan cerca a un grupo humano tan distinto y tan abundante. Abundante hasta el punto de llegar a desequilibrios tan grandes en Manila como de 2.000 españoles, como mucho, frente a 10.000, 20.000 y a veces 30.000 chinos a lo largo del siglo XVII. Españoles y chinos no solo eran distintos étnicamente, sino que se percibían mutuamente con culturas muy diversas y ambas bien conformadas ${ }^{28}$. En Filipinas, los chinos se incorporaron como extranjeros y no estuvieron sujetos a tributo ni a servicios personales como estaban los filipinos. Sus obligaciones fiscales fueron el pago de impuestos al comercio, el pago de licencias para establecerse en las islas, también el pago de licencias temporales para juegos de azar, especialmente el juego de metua que hacían en las fiestas del año nuevo chino, y muchas ayudas extraordinarias, que prestaban de buen grado para mantenerse en las mejores relaciones con las autoridades de Manila.

En una descripción de los chinos que hizo en 1576 el gobernador Francisco de Sande, señaló que por todas las islas Filipinas los chinos eran conocidos como sangleyes, es decir, como gente que viene y va aludiendo al comercio regular anual con Manila $^{29}$. El término indicaba una cercanía de los chinos, pero también esa referencia a gente que viene y va, era una alusión a gente extraña, a gente que no pertenecía al mundo filipino ni al mundo español. En otras palabras, eran claramente "otros", aunque fueran vecinos.

Durante el siglo XVI, salvo en los momentos en que se impusieron los proyectos de conquista que no aprobó la Corona, los españoles tuvieron una imagen de los chinos de Filipinas en la que el temor y la sospecha permanecieron mitigados. Los cambios más importantes llegaron por las consecuencias desastrosas del primer alzamiento chino de octubre de 1603 y de la primera expulsión masiva de chinos que se decretó por su causa.

\footnotetext{
27 Ch'en Ching-Ho: The Chinese Community in the Sixteenth Century Philippines, Tokyo, 1968, p. 90.

28 Estos problemas no fueron originales de la época española. Sobre las dificultades de integración de los chinos en Filipinas en época contemporánea se puede ver el trabajo de WiCKBERG, Edgard: «Anti-Sinicism and Chinese identity options in the Philippines», en СніRот, Daniel y ReID, Anthony (eds.): Essential outsiders: Chinese and Jews in the modern transformation of Southeast Asia and Central Europe, Seattle y Londres, University of Washington Press, 1997, pp. 153-183.

${ }^{29}$ AGI, Filipinas, 6: Francisco de Sande, gobernador, al rey. Manila, 7 de junio de 1576.
} 
El alzamiento no fue completamente inesperado, algunos vecinos de Manila habían advertido reiteradamente del peligro que suponía una presencia china tan numerosa y tan cercana. En todo caso, después del alzamiento de 1603, las numerosas muertes sufridas por los dos bandos y la comprobación de las pérdidas económicas que acompañaban a la ausencia de los chinos, marcaron la relación de dependencia y los sentimientos de temor y recelo. Por otra parte, el rápido regreso de los chinos a Manila, que ya había recuperado la normalidad en 1606, también dejó bien marcado para el futuro el convencimiento de los chinos de las ventajas que les proporcionaba mantener la cercanía con los españoles ${ }^{30}$.

Todavía se reforzarían estas actitudes a lo largo del siglo XVII, a pesar de otros episodios de enfrentamiento ocurridos en 1639, 1662 y 1686, episodios que terminaban con la expulsión de los chinos o con planteamientos sobre la conveniencia de expulsarlos. Al final, invariablemente terminaba imponiéndose la realidad de la dependencia que la comunidad española de Manila tenía de los sangleyes del parián y el mundo chino de Manila se recomponía a notable velocidad. Por eso, la administración colonial de Manila tomó la determinación de establecer un número máximo de sangleyes radicados en las islas, aunque la realidad mostró la dificultad de aplicar esta medida ${ }^{31}$.

A fines del siglo XVII, la Corona se planteó seriamente la conveniencia de radicalizar su actitud respecto de los chinos, planteando a las autoridades de Manila la necesidad de expulsar de Filipinas a los chinos no cristianos y haciendo que los que llegaban cada año en los champanes regresaran inmediatamente después de terminar la compraventa de mercancías con los manileños. La Real Cédula de 1686 dejó abierta una puerta a los chinos infieles para permanecer en las islas si se convertían al cristianismo, y estableció un plazo de dos meses para estudiar los casos que se $\operatorname{presentaran}^{32}$.

Para hacer balance, podría decirse que los españoles habían aprendido a fines del siglo XVI que su economía dependía de los chinos por completo, lo cual significaba que debían aprender a convivir con ellos tanto para su propia supervivencia como para que, al menos algunos, pudieran hacer una buena fortuna antes de regresar a México o a España. Desde luego, debe entenderse que esto afectaba tanto a las personas como a la continuidad de Filipinas como dominio español. También a lo largo del siglo XVI se había ido perfilando la imagen del chino, como original, como comerciante, hábil artesano de cualquier oficio, buen agricultor y pescador y acaparador de moneda de plata.

\footnotetext{
30 Sobre los alzamientos del siglo XVII y el proceso de expulsión ver GARCíA-ABÁsolo: «Relaciones entre españoles y chinos...», op. cit. (nota 20).

31 Después del alzamiento de 1603 el cabildo de Manila propuso que hubiera en Manila hasta 3.000 chinos para los abastos y servicios, y el gobernador Pedro Bravo de Acuña elevó el número a 4.000 para todas las islas (El cabildo de Manila al rey, Manila, 9 de diciembre de 1603; Pedro Bravo de Acuña al rey, Manila, 21 de diciembre de 1603: AGI, Filipinas, 27).

32 Real Cédula al presidente y oidores de la Audiencia de Manila, ordenándoles que hagan que todos los sangleyes que residan en Filipinas, y que no se hayan convertido al Cristianismo en el plazo de dos meses, salgan de esas islas a la mayor brevedad. A los sangleyes que vayan a comerciar sólo se les admitirá el tiempo de la feria, y los que se cristianicen y quieran quedarse se reducirán al Parián de la ciudad de Manila, y si son labradores o de otros oficios se les permitirá residir fuera de él. Buen Retiro, 14 de noviembre de 1686: AGI, Filipinas, 331, L.8, ff. 84v-85v.
} 
Sin embargo, el chino aparecía también como peligroso por la posibilidad de alzarse contra los españoles, e igualmente como peligroso por la influencia que su comportamiento moral y algunas manifestaciones de su religión tenían entre los neófitos filipinos e incluso entre los españoles cristianos viejos. Pueden citarse, por ejemplo, las polémicas suscitadas por la asistencia de los españoles a las comedias y celebraciones del año nuevo chino. Para la comunidad española, encerrada en las murallas de Manila, la asistencia a estas celebraciones era un elemento de diversión exótico extraordinario, pero los religiosos llamaron la atención de las autoridades de la ciudad, advirtiendo que asistir a estas fiestas era participar en actividades religiosas chinas. Las fiestas chinas continuaron celebrándose en el parián, el barrio chino fuera de las murallas de Manila, con los desfiles de máscaras y dragones y con el acompañamiento de fuegos artificiales, pero fue prohibida la asistencia de los españoles porque los religiosos las calificaron como celebraciones propias de "gente extraña que viene a sembrar idolatrías y supersticiones en tierra de cristianos". El problema se estaba planteando entonces también en China, a causa de las variaciones de los programas de adaptación cultural promovidos por San Francisco Xavier, que Mateo Ricci siguió fielmente y que su sucesor, Nicolás Longobardi, interpretó de otro modo ${ }^{33}$. Lo mismo que en China, en Manila, los problemas derivados de los ritos chinos incrementaron la desconfianza entre chinos y españoles.

\section{LOS REMEDIOS}

De ordinario, se consideró que el mejor remedio para solucionar estos problemas era la asimilación de los chinos por medio de la conversión al cristianismo. Los religiosos tuvieron el razonable criterio de que sus deseos de convertir China al cristianismo empezaban por las conversiones de los sangleyes de Filipinas. Esto dentro de un contexto evangelizador que introducía cuestiones nuevas de fondo, como las derivadas de los ritos chinos, y de forma, como la tolerancia con las costumbres chinas que no estuvieran abiertamente contra la doctrina evangélica.

Los españoles trataron de organizar la convivencia con los chinos de manera que fuera posible aprovechar las ventajas y eliminar los inconvenientes que implicaba su presencia. Lo hicieron por medio de tres medidas que fueron aplicadas simultáneamente: la regulación de las entradas de chinos en Filipinas, el control fiscal y el control espacial. La regulación de las entradas y el control fiscal llegaron a identificarse, porque los chinos que se quedaban en las islas estaban obligados a pagar una licencia de radicación, que se convirtió en una importante cantidad de recursos públicos. El control espacial se intentó conseguir concentrando a la población china en el parián, barrio propio fuera de las murallas pero a tiro de cañón de las baterías.

En la realidad, no fue posible poner control en las licencias de radicación, que dieron lugar a muchos fraudes de los que se beneficiaron con frecuencia los oidores

\footnotetext{
33 Sobre Mateo Ricci y Diego Pantoja en China se puede ver el trabajo de KaI, Zhang: Diego de Pantoja y China. Un estudio sobre la "Política de Adaptación” de la Compañía de Jesús, Beijing, Agencia Española de Cooperación Internacional del Ministerio de Asuntos Exteriores, 1997.
} 
de la Audiencia de Manila, ni tampoco se pudo evitar que los chinos terminaran estableciéndose fuera del parián, especialmente en los alrededores de Manila. Después se fueron extendiendo por la isla de Luzón y por el resto del archipiélago. Por otra parte, en el proceso de asimilación del chino en el espacio filipino y en las categorías mentales de los españoles, progresivamente fue destacando como elemento clave la religión, de manera que las conversiones al cristianismo fueron utilizadas también como filtro depurador de la comunidad china. En general, el sangley y el mestizo de sangley cristianos eran mejor asumidos por el mundo español porque estaban más cerca de los españoles.

Son muy abundantes los testimonios en los que se puede comprobar la mayor cercanía y confianza de los españoles hacia los sangleyes cristianos, a los que llegaron a encomendar servicios fundamentales para el abasto de Manila. Los panaderos de la ciudad fueron chinos habitualmente $\mathrm{y}$, además, los documentos hablan de la calidad y variedad del pan. Sin embargo, en ocasiones, el incremento de la tensión en la convivencia entre españoles y chinos dio lugar a situaciones pintorescas. En 1686, cuando todavía colgaban a las puertas del parián los cuerpos de algunos chinos ajusticiados como sospechosos de preparar una revuelta, algunos vecinos de Manila acusaron a los panaderos de haber metido vidrio molido en el pan para atentar contra la vida de los españoles.

Al final, el pleito se anuló y los panaderos chinos fueron absueltos, pero los autos son muy interesantes por los testimonios que vecinos de Manila muy cualificados hicieron en apoyo de la inocencia de los sangleyes. Entre ellos podemos citar al prior del Convento de San Pablo, al maestre de campo Fernando de Bobadilla y al almirante Juan de Vargas Machuca, padrino de bautismo de uno de los acusados, el panadero Juan de Vargas. El testimonio de estos y de otros muchos vecinos de Manila estaba de acuerdo con la argumentación del abogado defensor en la causa, que mostraba la incoherencia de la acusación porque los sangleyes panaderos

son casi vecinos de esta ciudad, por estar algunos casados en ella y con hijos, y no es de presumir que tuviesen intención de matar a los españoles, cuando en su conservación tienen mis partes la suya y de sus familias.

En los cuatro hornos de Manila trabajaban entonces 37 sangleyes, de los cuales 32 eran infieles y cinco cristianos. La media de edad de los cristianos era de casi 50 años, la de residencia en Manila de más de 25 años, tres de ellos eran cabezas de horno y dos estaban casados, uno con una filipina y otro con una mestiza de sangley. Algunos de ellos hablaban buen español ${ }^{34}$.

A través de cuestiones como la de los panaderos, se entiende que el factor fundamental para la asimilación y la convivencia pacífica era la conversión. Por eso, a

34 Testimonio a la letra de los autos que en virtud de comisión del superior gobierno sustanció, feneció y concluyó el señor oidor Dr D Pedro Sebastián de Bolívar y Mena sobre la sublevación de los sangleyes extramuros el año pasado de 1686. $1^{\text {a }}$ Vía 1687, ff. 918 y ss.: AGI, Filipinas, 67. Más sobre el tema en GarcíA-ABÁsolo, Antonio: «Conflictos en el abasto de pan de Manila en 1686: multiculturalidad y pan», en García Bernal, Manuela Cristina y Olivero Guidobono, Sandra (coords.): El municipio indiano: relaciones interétnicas, económicas y sociales: Homenaje a Luis Navarro García, Sevilla, Secretariado de Publicaciones de la Universidad, 2009, pp. 283-299. 
fines del siglo XVII, se determinó la expulsión de Filipinas de los chinos infieles. La orden permitía que los labradores y artesanos chinos cristianos se establecieran en el lugar que desearan de las islas, mientras que los comerciantes cristianos debían residir obligatoriamente en el parián. El comercio de los chinos que llegaban en sus champanes todos los años, que era vital para la economía colonial, no se interrumpió, pero estos comerciantes no podían salir del parián y tenían que regresar a China cuando terminaban la ventas.

La aplicación de esta orden no fue fácil, por el temor a que la expulsión de los chinos infieles paralizara la vida económica de Filipinas. En todo caso, se produjo un debate largo, de casi medio siglo, que dio lugar a gran cantidad de documentación, en la que se incidía nuevamente en la importancia de la conversión, es decir, del elemento religioso, en el proceso de asimilación del chino.

Oficialmente, el proceso de expulsión de los chinos no cristianos terminó en 1755 con la salida de las islas de 3.693, cantidad que no reflejaba el número real de chinos infieles que andaban descontrolados por las islas. Hay muchos testimonios de la presencia de sangleyes infieles y cristianos incluso en provincias lejanas de Manila. En 1731, el alguacil mayor de Manila José de Memije y Quirós consideraba la necesidad de que, en adelante, no se permitiera a los sangleyes residir en ningún pueblo de las provincias, "además de los que hoy residen, que para remover a éstos se han de tocar gravísimos inconvenientes" ${ }^{35}$. De esto se infiere también la aceptación habitual en las provincias de los mestizos de sangley, a los que ni siquiera menciona.

Para valorar la envergadura del problema con datos precisos, disponemos de los resultados de las visitas hechas a las provincias de la comarca de Manila por el oidor Pedro Calderón Enríquez en la primera mitad del siglo XVIII. En 1741 había en esa zona 25.000 mestizos de sangley, la cuarta parte de la población tributaria total, y a esta cantidad había que añadir más de 4.000 chinos infieles en el parián y otros 4.000, también infieles, en los alrededores de Manila. La incorporación de los mestizos de sangley había sido buena y todos los testimonios suelen ser favorables a su presencia en Filipinas. Vamos a tomar dos de los más cualificados: el de la Audiencia de Manila, que decía al rey en 1695 que los mestizos de sangley se criaban y educaban como sus demás vasallos, sin distinción alguna. Y el del arzobispo de Manila Juan Ángel Rodríguez, que también se dirigió al rey en términos similares en 1738: "los mestizos son muy útiles a estas islas y contrarios a los mismos sangleyes" ${ }^{36}$. Sin embargo, es necesario precisar el testimonio de la Audiencia, porque puede dar a entender que había una identidad demasiado grande entre los filipinos y los mestizos de sangley, y no era así. En las tasaciones realizadas en la provincia de Tondo en 1740, Calderón Enríquez determinó reducir "todas las castas de gente tributante a padrón y cabecerías". Como había comprobado que en algu-

${ }^{35}$ Dictamen del alguacil mayor de Manila, José de Memije y Quirós, miembro de la Junta convocada en Manila por el gobernador Fernando Valdés Tamón para estudiar la conveniencia de la expulsión de los sangleyes de Filipinas: AGI, Filipinas, 202, N1, R4.

36 AGI, Filipinas, 202: la Audiencia de Manila al rey. Manila, 18 de junio de 1695; AGI, Filipinas, 202: Juan Ángel Rodríguez, arzobispo de Manila, al rey. Manila, 20 de junio de 1738. 
nos pueblos el número de mestizos de chino era igual o mayor que el de filipinos, "para templarles el sentimiento de ser reducidos a barangayes como los indios", de acuerdo con el gobernador, dispuso que,

en el pueblo que llegasen a 300 tributos tuviesen gobernadorcillo separado y asiento en las iglesias éste y sus oficiales, y los cabezas en banco al lado de la epístola, dejando el del evangelio a los indios, como lo tenían. Y para no darles motivo de discordia, les ordené que en llevar las insignias en las procesiones tomase cada uno las de su lado, según estaban en la iglesia. Y señalé el modo en que habían de proceder en lo jurisdiccional.

Todavía más distinción, porque estableció para los indios un tributo de 10 reales y para los mestizos de chino de 20, por ser más industriosos ${ }^{37}$. Esto muestra que la identificación no era tal y que los problemas de identidad de los mestizos de chino -que tendrían continuidad- se mostraron pronto.

En todo caso, -recuperando la cuestión central- el sangley rechazable era el sangley infiel, para el que el oidor Pedro Calderón y otras autoridades de Manila y Madrid reservaron el espacio mental que en España se había dedicado a judíos y musulmanes, es decir, la categoría de grupos con los que la única solución era la expulsión del país, una vez comprobado que una política de separación residencial era ineficaz en la práctica y especialmente grave en la convivencia de los sangleyes infieles con los indios cristianos. Los argumentos de derecho empleados por Calderón fueron desde las Sagradas Escrituras y las Partidas, hasta las disposiciones de las Recopilaciones de leyes de los Reinos de Castilla e Indias. De nuevo quedaba de manifiesto que el factor fundamental que hacía al chino distinto era su infidelidad. Calderón todavía precisa más este valor y lo pone por encima del conocimiento de la lengua, al proponer que a los sangleyes cristianos casados que residían en la comarca de Manila debía ponérseles plazo para que aprendieran español o la lengua del país, de manera que pudieran asistir a la doctrina en sus parroquias. Sólo si no aprendieran alguna de estas lenguas debía trasladárseles a algún pueblo con párroco conocedor del chino, es decir, a Tondo, Binondo o Santa Cruz ${ }^{38}$.

Por otra parte, una consecuencia muy importante de estas noticias es que la presencia de tan gran número de mestizos de sangley en la comarca de Manila había empezado a conformarla definitivamente como una zona de asimilación china por la conversión y el mestizaje chino-filipino.

\footnotetext{
37 AGI, Filipinas, 573A: Pedro Calderón Enríquez al rey, Manila, 8 de julio de 1758. Barangay era el nombre de una unidad familiar amplia, compuesta de padres, hijos, siervos y parientes: ver Morga: op. cit. (nota 19), p. 471.

38 AGI, Filipinas, 202: tercera representación que hace el licenciado Pedro Calderón Enríquez, oidor de la audiencia de Manila, al gobernador Gaspar de la Torre. Manila, 16 de junio de 1741.
} 


\section{CONCLUSIÓN}

Contempladas con la perspectiva del tiempo, las relaciones de dependencia de españoles y chinos en Filipinas revelan que ambos aplicaron poderosos factores de protección. Los chinos, con el dominio de la vida económica, haciéndose imprescindibles para asegurar su permanencia en el país; los españoles aprovechando a los chinos para asegurar la continuidad de una pequeña comunidad en Oriente, aplicando unos elementos de recuperación de recursos mediante el control fiscal y las ayudas extraordinarias -pero frecuentes- de los chinos, y protegiéndose de ellos por la vía de la asimilación a través de las conversiones.

Con todo, centrar la atención en exceso en las sublevaciones de los sangleyes y en las reacciones consiguientes de los españoles puede perturbar el acercamiento a otra realidad: la que contempla el esfuerzo de ambos grupos por entenderse, con la aceptación convencida de la inviabilidad de una vida separada. En las circunstancias actuales de un mundo globalizado, este es un aspecto de las capacidades del Imperio español que tal vez debería ser mejor valorado. 